\title{
Demandas obreras, resistencias empresariales y posicionamiento estatal en la construcción de derechos. Tucumán, 1946-1955*
}

\section{Workers' demands, entrepreneurial resistance and state positioning regarding rights construction, Tucumán, 1946-1955}

\author{
Florencia Gutiérrez \\ Instituto Superior de Estudios Sociales \\ Universidad Nacional de Tucumán \\ Consejo de Investigaciones Científicas y Técnicas \\ florenciagutierrezb@yahoo.com
} (Argentina)

\section{Resumen}

En Tucumán, el gobierno peronista puso en cuestión la concepción privada y asistencialista del techo y el cuidado de la salud obrera defendida históricamente por los empresarios azucareros y procuró avanzar, no sin dificultades, en estos sensibles problemas sociales. Así, en un contexto dominado por el rol tutelar y regulador del Estado nacional en la agroindustria, el avance de la sindicalización y el reconocimiento de inéditos derechos laborales, el problema de la asistencia médica y la vivienda obrera fueron recuperados por el gobierno provincial con el propósito de impulsar leyes que los convertían en derechos garantidos por

\footnotetext{
*. Versiones preliminares de este texto fueron presentadas en las IV Jornadas Política de Masas y Cultura de Masas. América Latina en entreguerras: miradas locales, nacionales y transnacionales realizadas en la Universidad Nacional de General Sarmiento, 2106 y en el Seminario Permanente Interinstitucional de Historia Política del Instituto de Investigaciones Dr. José María Luis Mora (México), 2106. Agradezco las sugerencias y observaciones recibidas en ambos eventos. Asimismo, cabe señalar que este artículo fue elaborado en el marco de los proyectos: "Las formas locales de la política. Actores, redes partidarias y dinámicas asociativas en el pueblo azucarero de Bella Vista, Tucumán, 1934-1966", financiado por la Agencia Nacional de Promoción Científica y Tecnológica y "La construcción social de lo político: cañeros y trabajadores en los pueblos azucareros, 1896-1966”, financiado por el Consejo de Investigaciones Científicas y Técnicas.
} 
los industriales. Sin embargo, la nueva coyuntura política, al tiempo que alentó estos cuestionamientos y construcciones, marcó sus límites y posibilidades. En síntesis, el objetivo de este artículo es analizar cómo, en el periodo estudiado, la salud y el techo obreros se disputaron en clave de derechos y de qué forma la definición del sector industrial como actor garante de los mismos tensionó las concepciones asistencialistas de los empresarios azucareros e interpeló al propio Estado peronista en función de sus obligaciones sociales.

Palabras Clave: salud; vivienda; Peronismo; Tucumán

\begin{abstract}
In Tucuman, the Peronist government questioned the private and assistentialism-oriented conception of housing and health care of workers. This conception was historically advocated by the sugar businessmen. The government tried to step forward, not without difficulties, with those sensitive social problems.

In a context dominated by the tutelary and regulatory role of the national State in agro-industry, plus the advance of workers' unionization and the recognition of unprecedented labour rights, the district government took into account the matters related to worker medical assistance and housing. These regulations were transformed into rights guaranteed by the sugar businessmen. However, the new political conjuncture, while encouraged new questionings and proposals, also established its limits and possibilities.

In summary, the objective of this article is to analyze how, in the period studied, worker health and housing were discussed in terms of rights and in what way the definition of of the industry sector as a guarantor of them placed strain on the assistentialism conceptions of the sugar businessmen and placed questioning on the social obligations of the Peronist State.
\end{abstract}

Keywords: health; housing; Peronism; Tucumán

$$
\propto \ddot{e} \propto
$$

\section{Introducción}

En diciembre de 1951 los obreros del ingenio San Pablo recuperaron la convocatoria pública lanzada por el presidente Juan D. Perón, quien invitó especialmente a los sindicatos a enviarle petitorios e inquietudes, los que serían evaluados y eventualmente incorporados al diseño del Segundo Plan Quinquenal. De puño y letra, los trabajadores le informaron al Presidente el "triste espectáculo" ofrecido por las "chozas miserables y los conventillos horribles" en que vivían, los que ponían en riesgo su salud física y moral. En su carta se pregunta- ban "de qué están hechos los hombres que dirigen los establecimientos industriales que no quieren ponerse a tono con el régimen social y humano en que vivimos". Finalmente, solicitaban la expropiación y loteo de terrenos de la fábrica para levantar pequeñas villas obreras. ${ }^{1}$ Por su parte, Ramón Pucheta, obrero del ingenio Concepción, le escribió a Perón para denunciar las condiciones del techo -que no eran adecuadas "para seres humanos"- y en lo

1. Expediente 11.289, caja 53, Fondo Secretaría Legal y Técnica de la Presidencia de la Nación (FSLTPN), Departamento Intermedio, Archivo General de la Nación (DI-AGN), Buenos Aires. 
referente a la asistencia médica señaló que "hay un hospital del establecimiento que carece de personal competente, si hay obreros enfermos de noche no hay quien lo atienda porque médicos internos no lo tienen, tampoco vienen a la casa cuando hay enfermos graves". ${ }^{2}$

Estas, y muchas otras cartas que le llegaron a Perón desde los pueblos azucareros, nos devuelven los términos en que los obreros permanentes vivenciaron el problema del techo y la asistencia médica, beneficios otorgados discrecionalmente por la patronal y atados a la pervivencia del vínculo contractual con la fábrica. ${ }^{3}$ En este contexto de preocupaciones, cabe precisar que desde la primera década del siglo XX, los empresarios azucareros articularon el otorgamiento de la vivienda obrera con un conjunto de servicios y beneficios que defendieron como iniciativas privadas, propias

2. Expediente 12.024, caja 405, FSLTPN, DI-AGN, Buenos Aires.

3. Desde fines del siglo XIX, la intensificación del cultivo e industrialización de la caña de azúcar definió el perfil productivo de Tucumán, al tiempo que transformó sensiblemente su entramado socio-laboral. A mediados de la década de 1940, la provincia contaba con 28 ingenios de mediana capacidad productiva y alta dependencia de productores de materia prima (cañeros), a diferencia de otros espacios provinciales (Salta y Jujuy) caracterizados por un modelo productivo concentrado, es decir, pocas fábricas con integración de cultivos y elaboración en una sola empresa. El universo productivo y laboral azucarero fue modelado por el ritmo periódico de la zafra, etapa marcada por la cosecha e industrialización del dulce y extendida entre los meses de mayo y octubre. Así, la estacionalidad de las labores y la complementariedad de las tareas de fábrica y de surco, propias de la condición agroindustrial azucarera, definieron la composición del numeroso y variopinto mundo del trabajo. Este último reconocía diferencias en función del lugar de trabajo (fábrica o surco) y el vínculo contractual con los propietarios del ingenio, ya fuera que los obreros laboraran todo el año en la fábrica o el cañaveral (permanentes) o lo hicieran únicamente en la época de la zafra (temporarios). de un "elevado sentimiento de humanidad y de justicia social". A decir del Centro Azucarero Argentino (en adelante, CAA), corporación que organizaba a los empresarios de la agroindustria, algunas expresiones de la "acción social" hacían "perfectamente sabido" para todos

que las fábricas prestan servicios hospitalarios y de asistencia gratis (...) que ellas pagan la enseñanza que se imparte en las escuelas de las poblaciones respectivas; que el obrero cuenta con habitación de material para su familia en los alrededores de las mismas; que los ingenios distribuyen alimentos gratis a las familias de los obreros en los períodos de receso de las zafras; que existen salas de espectáculos, campos de deportes, cines al aire libre (CAA, 1943, p. 25). ${ }^{4}$

Esta concepción, sustentada en el asistencialismo y defendida en términos de incumbencias personales, propias de un espacio privado, fue refractaria a los intentos de convertir los beneficios en obligaciones, noción que se inscribía en el global rechazo empresarial a la intervención y regulación del Estado en materia laboral. ${ }^{5}$ Así sucedió, por ejemplo, con la ley de asistencia médica obligatoria, permanente y gratuita en los ingenios, la que fue propuesta por el socialismo y votada por la Legislatura provincial en 1925 pero estuvo destinada a su incumplimiento. ${ }^{6}$ La ley establecía que las fá-

4. Para conocer los patrones de la vida social en los ingenios azucareros del norte argentino entre 1870 y 1930 remitimos a Campi (2009).

5. Este posicionamiento generó tensiones, particularmente desde la creación del Departamento Provincial de Trabajo (1917) y el incipiente avance legislativo promovido por los socialistas y radicales en la Legislatura provincial en las décadas del veinte y treinta. Remitimos, especialmente a Landaburu (2014), Landaburu y Lenis (2015) y Ullivarri (2016).

6. La posibilidad de los empresarios para impedir, 
bricas debían disponer de una enfermería (con determinado números de camas en función de la cantidad de trabajadores) y una sala de primeros auxilios, a cargo de un médico con residencia permanente en el establecimiento. El plazo fijado para su construcción era de 6 meses, la falta de observancia habilitaba al poder ejecutivo a su construcción y a recuperar lo invertido por vía de apremio.

En esa ocasión los industriales impulsaron una campaña de cuestionamientos y la presentación de una contrapropuesta orientada a la construcción de un hospital zonal. ${ }^{7} \mathrm{El}$ proyecto de los empresarios no llegó a convertirse en ley y el incumplimiento de la legislación fue una constante. La resistencia de los industriales -anclada en la noción de que salud "era un deber del Estado y no del capital privado"- impidió transformar la asistencia médica en una "práctica obligatoria" pero: "comenzó a quebrar la arraigada idea respecto a un mundo azucarero sostenido sobre una política social sin Estado, donde primaban un sistema de patronato

durante décadas, el avance del Estado y la legislación laboral en el mundo del trabajo azucarero expresó su "poder de clase" y la confirmación del imaginario personal y privado en el que inscribían las relaciones laborales. Por ejemplo, en 1918 volvió a reglamentarse el descanso dominical, aprobado por primera vez en 1907, pero la norma exceptuó de este derecho a los peones azucareros ocupados en las tareas agrícolas para quienes el día de descanso no suponía la obligación del pago del jornal. Algo similar ocurrió con la ley de indemnizaciones para obreros y empleados (1933) que "había sido interpretada en la provincia y la sentencia excluía de sus beneficios" a quienes no fueran obreros y empleados del comercio (...) vale decir que todo el personal de la industria azucarera estaba exento de los beneficios de las indemnizaciones". Testimonio de Carlos Aguilar. 1988, p. 9. Archivo Privado Ana María Aguilar (APAMA), Tucumán.

7. Antecedentes sobre las leyes, pp. 2.018-2.029 y 2.0272.116, 1948, Ministerio de Salud Pública y Asistencia Social (MSPAS), Tucumán. y de obligaciones morales entre empleados y patrones" (Ullivarri, 2016, pp. 873-874).

E1 problema de la vivienda obrera azucarera nunca alcanzó a legislarse. Sin embargo, en la década del veinte los radicales impulsaron diversos proyectos en la Legislatura; el primero, formulado en 1920, propiciaba la expropiación de terrenos en zonas cercanas a los ingenios con el objetivo de crear villas obreras. Los lotes serían asignados a los trabajadores, quienes dispondrían de cinco años para pagar (de forma mensual y sin intereses) la propiedad. Ocho años más tarde, el radicalismo replicó la iniciativa al presentar un proyecto que facultaba al poder ejecutivo a expropiar terrenos circundantes a las fábricas, primer paso para la construcción de casas baratas que serían financiadas por la Caja Popular de Ahorros de la Provincia. ${ }^{8}$ La imposibilidad de convertir en ley estas iniciativas expropiatorias, que avanzaban sobre los empresarios y ubicaban al Estado como el impulsor y garante de la vivienda obrera, confirmó la concepción del techo como un beneficio temporal y discrecional otorgado por los industriales. En 1937, infructuosamente el radicalismo impulsó un nuevo proyecto destinado a los empleadores agrícolas, quienes debían construir viviendas higiénicas y baratas (para los obreros permanentes y transitorios) en un plazo no mayor de dos años desde la promulgación de la ley. Para facilitar su construcción, el Banco de la Provincia y la Caja Popular de Ahorros concederían créditos a los industriales. ${ }^{9}$ Así, tanto en lo que respecta a la vivienda y la salud obrera, "la acción del Esta-

8. Remitimos a Landaburu (2014, pp. 132-133 y 226227).

9. Se presentó un proyecto declarando obligatoria la construcción de viviendas para obreros (26 de mayo de 1937). La Gaceta, p. 8. Agradezco a María Ullivarri por facilitarme esta documentación. 
do estuvo siempre muy condicionada por los intereses azucareros, cuyo rol protagónico en la historia provincial volvía dificultosa la tarea de legislar sobre sus prácticas y sobre las relaciones laborales que eran consideradas de índole privada" (Ullivarri, 2017, p. 286)

Con nuevos bríos, la llegada del peronismo puso en cuestión la concepción privada y asistencial del techo y el cuidado de la salud obrera y procuró avanzar, no sin dificultades, en estos sensibles problemas sociales. En una coyuntura dominada por el rol tutelar y regulador del Estado nacional en el complejo agroindustrial, analizaremos cómo el gobierno provincial impulsó proyectos de ley que convertían la asistencia médica y el otorgamiento de la vivienda en derechos garantidos por los industriales. Como contrapunto, nos preguntamos de qué forma la nueva coyuntura política, al tiempo que alentó estos cuestionamientos y construcciones, marcó sus límites y posibilidades.

En síntesis, la propuesta de este artículo es analizar cómo la experiencia obrera y las prácticas de los empresarios fueron resignificadas por la coyuntura política habilitada por el peronismo. En tal sentido, a manera de hipótesis, sugerimos que el avance del gobierno provincial sobre tradicionales prerrogativas empresariales impulsó un campo de fuerzas donde la salud y el techo obreros fueron disputados y actualizados en clave de derecho. Estas demandas lideradas por el sindicalismo azucarero no sólo cuestionaron la concepción asistencialista empresarial, sino que tensionaron al propio Estado peronista, en tanto las agencias provinciales y nacionales disintieron en la delimitación del actor garante de estos derechos.

\section{E1 Estado peronista y los empresarios: tensiones en la construcción de derechos}

El golpe militar de junio de 1943 alentó el papel tutelar y regulador del Estado en el complejo azucarero, redefinición que, proyectada a lo largo de la primera década peronista, impactó en el mundo laboral azucarero. ${ }^{10}$ Algunas de las manifestaciones más nítidas de este nuevo posicionamiento fueron: el avance de la sindicalización expresado en la multiplicación de sindicatos de fábrica y surco que, en 1944, convergieron en la Federación Obrera Tucumana de la Industria Azucarera (en adelante, FOTIA); la promulgación de decretos nacionales que regularon las relaciones laborales y auspiciaron inéditos derechos; y la consolidación de un funcionarado, liderado por la Delegación Regional de la Secretaría de Trabajo

10. Con el golpe de Estado de 1944, la presencia tutelar del Estado nacional y su intención de diseñar una política integral para la agroindustria se plasmaron en el decreto 678 que, promulgado en enero de 1945 , sentó las bases sobre las que descansaría el funcionamiento azucarero. El decreto avanzó en la creación de un Fondo Especial de Compensación y Asistencia Social conformado con el aumento del precio del azúcar y destinado a compensar a cañeros e industriales por los mayores costos productivos. Así, este Fondo, que reconocía y distribuía los mayores costos de producción y los derivados de la política social, posicionó al Estado nacional en el centro de la puja sectorial, involucrándolo en la compleja tarea de regular las demandas y asignar a cada actor retribuciones equitativas. A partir de 1949, en contexto nacional de crisis económica, el Estado nacional le imprimió un nuevo giro a la política azucarera, reformulación que implicó avanzar en un proyecto racionalizador. A partir de 1952, este plan se profundizó al elevarse los rendimientos mínimos sobre los que se fijaba el precio de la caña y de su industrialización, al tiempo que se avanzó en la total eliminación de los precios sobre la base del peso y se establecieron en Tucumán zonas no aptas para el cultivo. Los lineamientos de la política azucarera fueron analizadas en Bravo y Gutiérrez (2014) y Bustelo (2016). 
y Previsión (en adelante, DRSTyP), dispuesto a franquear los portones de los ingenios en procura del cumplimiento de la novel legislación. Al unísono, las históricas vivencias de los trabajadores, sus postergadas reivindicaciones y sus sentidos de lo justo incidieron en el proceso de organización y construcción de derechos e impulsaron demandas que muchas veces desafiaron los límites del propio Estado peronista. $^{11}$

El aliento estatal a la sindicalización revirtió intermitentes $y$, en gran medida, frustrados esfuerzos de organización obrera. ${ }^{12} \mathrm{La}$ multiplicación de sindicatos por la veintena de ingenios y la fundación de FOTIA sintetizaron una de las grandes novedades en el mundo del trabajo agroindustrial de los años cuarenta. El decidido compromiso de los funcionarios de la DRSTyP con la fundación de sindicatos, anhelo signado durante décadas por la imposibilidad, fue modelado por esas históricas postergaciones, al tiempo que gravitó sensiblemente en la experiencia de los trabajadores tucumanos. Al interior de los ingenios, el creciente poder obrero promovió una redistribución del poder fabril en detrimento de tradicionales prerrogativas de los industriales

11. Las implicancias del proceso de sindicalización azucarera fueron estudiadas por Rubinstein (2005) y Gutiérrez (2014).

12. En términos de organización laboral, la Unión General de Trabajadores de la Industria Azucarerafundada en 1935 y vinculada al socialismo- pervivió hasta 1942 convirtiéndose en la expresión sindical más importante de los años treinta. Sin embargo, la primigenia idea de constituir una organización de segundo grado no se concretó por la imposibilidad de multiplicar la fundación de sindicatos de base. Esta situación se imbricó con un posicionamiento institucional "reticente a declarar huelgas o realizar acciones directas", que impidió el desborde de los reclamos particulares. Ullivarri (2011). -como la organización y administración de la fuerza laboral y el control de los procesos productivos- $\mathrm{y}$ se proyectó en la interpelación a los beneficios otorgados por los empresarios (Gutiérrez, 2014).

El proceso de sindicalización fue acompañado del involucramiento del Estado en materia laboral, sucesivos decretos presidenciales -particularmente entre 1945 y 1949 - regularon las condiciones laborales en los ingenios y cañaverales y promovieron inéditos derechos, muchos de ellos profundizados a lo largo de la primera década peronista. La institucionalización del escalafón y su correlato salarial, el reconocimiento del aguinaldo y el salario familiar, la modificación de la jornada laboral en las tareas insalubres, las condiciones para acceder a la mensualización, el suplemento salarial en función de la antigüedad, entre otros, fueron reconocidos por sucesivos decretos presidenciales que regularon el universo laboral agroindustrial (Gutiérrez, 2016). El avance de estos derechos, las denuncias obreras por los incumplimientos de la patronal y la mayor receptividad y presencia de las agencias estatales para lograr su observancia horadaron la concepción privada de las relaciones laborales defendida por los industriales y coadyuvaron a cuestionar el poder de los empresarios en las fábricas. ${ }^{13}$

El papel regulador y tutelar del gobierno nacional en la esfera laboral azucarera reconoció un límite, en tanto su avance no interpeló los beneficios que los industriales otorgaban a los obreros en materia de vivienda y salud. Sin embargo, el gobierno provincial avanzó sobre estos sensibles problemas con el propósito de

13. El posicionamiento del empresariado azucarero en materia laboral en las décadas previas al peronismo fue analizado por Landaburu y Lenis (2015) y Ulivarri (2013). 
convertirlos en obligaciones patronales. Así, en noviembre de 1946 el gobernador Carlos Domínguez (1946-1950) presentó a la Legislatura un proyecto de ley elaborado por el Ministro de Salud y Asistencia Social, Dr. Alberto Navarro, que impulsaba la asistencia médica gratuita y obligatoria en todos los establecimientos industriales, comerciales, agrícolas, forestales y ganaderos, cuyo personal no sea menor de 200 personas. Por tanto, el proyecto recuperaba y profundizaba el espíritu de la incumplida ley de 1925 y convertía a los industriales en sus directos destinatarios.

La iniciativa hacía recaer en los empresarios la construcción, sostenimiento y funcionamiento de una compleja infraestructura hospitalaria. En efecto, contemplaba la contratación de un médico jefe y un médico sub-jefe full time que residirían de forma permanente en los pueblos azucareros y serían acompañados por auxiliares (odontólogos, parteras, enfermeros, visitadora de higiene, entre otros), quienes no estaban obligados a vivir en el predio del ingenio. Asimismo, se precisaba que el servicio hospitalario debía incluir consultorios, sala de curaciones, laboratorios de rayos $\mathrm{X}$, farmacia, servicio de cirugía, odontología y obstetricia y disponer de "todos los medios necesarios (medicamentos, alimentos, drogas, instrumental, etc.)" para la completa atención de los enfermos. Los gastos de construcción y sostenimiento del hospital, así como los sueldos del personal, serían costeados "por el propietario del inmueble donde se ubique el establecimiento fabril o comercial". ${ }^{14} \mathrm{E} 1$ tiempo fijado para la construcción

14. Ley de asistencia médica permanente y gratuita en los establecimientos industriales de Tucumán (enero de 1947). La Industria Azucarera, 639, pp. 13-14. Biblioteca de Estación Experimental Agroindustrial Obispo Colombres (BEEAOC), Tucumán y Decreto reglamentario de la ley de asistencia médica obligatoria y equipamiento de los hospitales no podía superar los seis meses a partir de la reglamentación de la ley, en caso de incumplimiento el poder ejecutivo provincial tenía facultades para imponer multas y, en última instancia, podía mandar a construir a cuenta de los industriales las instalaciones sanitarias. ${ }^{15}$ Finalmente, en enero de 1947 se aprobó la ley 2.018 que establecía la asistencia médica gratuita y obligatoria en los ingenios. ${ }^{16}$

En enero de ese mismo año, la Legislatura aprobó un proyecto de ley que, presentado por el gobernador de la provincia, promovía la construcción de viviendas en los ingenios Marapa y Ñuñorco. En estas fábricas, donde el Estado provincial tenía una importante participación a través de la Caja Popular de Ahorros, se avanzó en un plan de construcción de viviendas para los empleados y obreros perma-

en los establecimientos industriales de Tucumán (febrero de 1947). La Industria Azucarera, 640, p. 80. BEEAOC, Tucumán. En 1946, en Jujuy también se sancionó una ley que establecía la obligatoriedad de la asistencia médicahospitalaria gratuita por parte del propietario para todos los trabajadores y sus familias, fuesen permanentes o temporarios, en los establecimientos comerciales e industriales que dispusieran de un personal no inferior a 200 personas. Remitimos a Jerez (2016, pp. 9-10).

15. Cámara de Diputados. Diario de Sesiones (CDDS). 28 de diciembre de 1946, pp. 765-768. Biblioteca de la Legislatura de la Provincia de Tucumán (BLPT), Tucumán.

16. Sin embargo, el histórico incumplimiento de la legislación sanitaria asociada a los ingenios llevó al diputado Julio Mirandou a señalar que la exigüidad de las multas atentaba contra la observancia de la ley, cuestionamiento que promovió la elevación de las multas, mismas que podrían oscilar entre $\$ 500$ y $\$ 50.000 \mathrm{~m} / \mathrm{n}$ según la gravedad de la infracción. De esta forma, la ley 2.018 fue modificada parcialmente por la 2.029 (en lo referente a las multas) y el 14 de febrero de 1947 el gobernador Domínguez reglamentó, mediante un decreto, la asistencia médica obligatoria y gratuita en los establecimientos industriales. 
nentes. ${ }^{17} \mathrm{~A}$ los pocos meses, en septiembre de 1947, el gobierno provincial intentó profundizar los alcances de esa ley y, por iniciativa del Ministro de Salud, presentó a la Legislatura un proyecto que precisaba el tipo de vivienda que todos los empresarios debían facilitar a sus empleados y obreros de fábrica y surco. El proyecto señalaba que las construcciones debían contemplar las calidades técnicas de los materiales (pisos de mosaico o baldosas y muros revocados y con capas aisladoras), contar con ventilación e iluminación suficientes, disponer de cocina higiénica, baño, w.c., bañadera, cámara séptica, agua potable, energía eléctrica y brindar el número suficiente de habitaciones con una capacidad de 22 metros cúbicos por persona que la habite. Asimismo, debían contar con una galería y una parcela de tierra para huerta o jardín. Las casas colectivas sólo podían destinarse a trabajadores solteros, sin familia y mayores de 18 años. El incumplimiento de esta obligación implicaría el cobro de multas que oscilarían entre los 500 y 2.000 pesos por vivienda en infracción.

17. Esta ley autorizaba a la Caja Popular de Ahorros a utilizar fondos de reserva para la construcción de viviendas en los ingenios Marapa y Nuñorco, las mismas serían adjudicadas a los empleados y obreros permanentes. Los plazos, montos y condiciones de los préstamos, así como las dimensiones de las viviendas, tendrían en cuenta el número de familiares y el sueldo o jornal percibido. La cuota de amortización no podía superar el $20 \%$ de la remuneración mensual, incluido el salario familiar. Véase: Ley 2.024 promulgada en Tucumán el 20 de enero, autorizando a la Caja Popular de Ahorros a invertir fondos en la construcción de viviendas para empleados y obreros de los ingenios Marapa y Ñuñorco (enero de 1947). La Industria Azucarera 639, pp. 28-29. BEEAOC, Tucumán y La Caja Popular construirá casas en Marapa y Ñuñorco (2 de octubre de 1946). La Gaceta. Archivo Diario La Gaceta (ADLG), Tucumán. La condición de sociedades mixtas con responsabilidad limitada del Marapa y Ñuñorco fue analizada por Bustelo (2016).
En su presentación frente a la Legislatura, el Gobernador subrayó que el proyecto contribuiría a superar el derecho de inviolabilidad del hogar proclamado por la democracia liberal, en tanto garantizaba la inviolabilidad de la vivienda obrera frente a "la amenaza de los males que se derivan de la sordidez, la insalubridad, la falta de higiene, la promiscuidad y el hacinamiento". ${ }^{18}$ Finalmente, la iniciativa -cuyo norte era avanzar en la construcción de una "democracia social"- no logró convertirse en ley, ni siquiera fue discutida. Infructuosamente, al año siguiente Domínguez replicaría su presentación en la Legislatura. ${ }^{19}$ Probablemente, la imposibilidad del tratamiento de este proyecto, en un cuerpo legislativo con importante presencia obrera y, en especial, azucarera, expresó las tensiones al interior del peronis-

18. Proyecto de ley sobre viviendas obreras en los ingenios de Tucumán (septiembre de 1947). La Industria Azucarera 647, p. 451. BEEAOC, Tucumán.

19. Resulta sugerente el contrapunto con la experiencia de la también azucarera provincia de Jujuy, en tanto allí el gobierno peronista logró avanzar en una normativa específica para la vivienda rural, misma que recuperó preocupaciones previas y cuyos destinatarios fueron, especialmente, los empresarios de la agroindustria. Como fue estudiado por Marcelo Jerez (2017) en 1947 la Legislatura aprobó ley 1.814 que, bajo la denominación ley de vivienda obrera, obligaba a todos los establecimientos o empresas de propiedad privada a proporcionar vivienda cómoda e higiénica a sus empleados, ya fueran permanentes o transitorios. En el poder ejecutivo recaía la obligación de establecer los plazos de su ejecución, así como el control de su cumplimiento, el que estuvo marcado por las resistencias e incumplimientos de la patronal. En tal sentido, el disímil derrotero que asumieron los proyectos de vivienda rural en Tucumán y Jujuy invita a desarrollar investigaciones comparativas tendientes a estudiar la capacidad de presión del empresariado azucarero en ambos espacios, la configuración y tensiones de las tramas partidarias peronistas provinciales y el impacto de la Fundación Eva Perón y las políticas crediticias en la construcción de viviendas rurales. Para el caso jujeño remitimos a Jerez (2017, pp. 314-320). 
mo. ${ }^{20}$ En efecto, frente a un Estado que avanzaba como garante del derecho a la vivienda, su delegación en los industriales promovía pujas de sentidos que, como veremos a continuación, también gravitaron en la ley de asistencia médica. Así, los límites de las demandas -cuyo punto álgido tuvo lugar en 1949 cuando los senadores aprobaron un proyecto de expropiación de ingenios que obligó al interventor del partido peronista provincial a frenar su discusión en la Cámara de Diputados- constituyen un observatorio privilegiado para analizar la arena de disputas, negociaciones y complejos equilibrios que atravesaron al peronismo tucumano. $^{21}$

En razón del disímil derrotero de los proyectos presentados por el Gobernador, el accionar de los industriales se concentró en el cuestionamiento de la ley de asistencia médica. En marzo de 1947, los empresarios publicaron una solicitada donde subrayaron que la salud era una responsabilidad del Estado, que debía

20. Entre 1946 y 1950, Mackinnon (2003) señala que en la Cámara de Diputados sobre un total de 34 diputados, 29 eran peronistas y 5 radicales; en la Cámara de Senadores 18 eran peronistas y uno sólo era radical. Por su parte, esta autora identifica 11 diputados provinciales de origen explícitamente obrero o que tienden a defender posiciones obreras y entre los senadores precisa que entre 9 y 11 defienden posiciones obreras. En síntesis, "en Tucumán la FOTIA o los legisladores de origen obrero componen la mayoría de la legislatura".

21. El avance expropiatorio sobre los terrenos lindantes a los ingenios, propiedad de los empresarios azucareros, con el propósito de avanzar en la colonización y loteo también marca un contrapunto entre las experiencias de las provincias azucareras. Mientras la Legislatura jujeña aprobó y logró avanzar en la expropiación, por ejemplo, en los pueblos de San Pedro y Ledesma, en Tucumán este tipo de política no sólo no logró concretarse, sino que su discusión legislativa desató una crisis que requirió de la mediación del interventor del partido peronista. Remitimos a Jerez (2017) y Mackinnon (2003, pp. 105110). "depender directamente de él, sin perjuicio de la cooperación de los habitantes". Como contrapartida, proponían la creación de policlínicos instalados en lugares estratégicos de la provincia, instituciones que los empresarios ayudarían a sostener. El Ministro de Salud y Asistencia Social interpretó la resistencia de los industriales "con la defensa de sus particulares intereses" y una "actitud de incomprensión y egoísmo" que se remontaba a 1925, con el incumplimiento de la primera ley de asistencia médica. ${ }^{22}$ Similares términos utilizó Navarro en su informe al Secretario de Salud Pública de la Nación, a quien le señaló que los industriales pretendían suplir sus "obligaciones ineludibles con un mínimo de erogación y con olvido de elementales deberes sociales". ${ }^{23}$ Los legisladores, muchos de ellos de extracción fotiana, recuperaron este postulado al momento de la sanción de la ley. En ese contexto, el diputado Segundo Moyano señaló que

esta es una noche de felicidad para nosotros los legisladores obreros. Todos sabemos cuál es la situación sanitaria de los obreros azucareros (...) Todos sabemos que solamente se recetan un purgante de sal o una cafiaspirina, cualquiera sea el mal que el enfermo tenga ¿¿A qué obedece eso? A la mezquindad de los dueños de ingenios, que solamente buscan la manera de aumentar su riqueza sin importarles para nada la miseria de los trabajadores. ${ }^{24}$

22. La asistencia médica en los establecimientos industriales de Tucumán (marzo de 1947). La Industria Azucarera 641,pp. 107-108. BEEAOC, Tucumán.

23. Antecedentes sobre las leyes, p. 68. MSPAS, Tucumán.

24. CDDS. 19 de diciembre de 1946, p. 860. BLPT, Tucumán. 
La ley pretendía erosionar la concepción de la asistencia médica como un beneficio discrecional o dádiva empresarial para instituirla como un derecho garantizado por los industriales. Así lo manifestó el diputado Enrique Zarlenga cuando señaló que el partido laborista cumplía con su palabra "al velar por la salud del pueblo entregándole esta conquista, no como una concesión caritativa, que es como se venía haciendo, sino como un derecho inalienable". ${ }^{25}$

Ahora bien, la construcción del derecho a la salud como una obligación patronal adquirió su plena significación al asociarse con el carácter distributivo del proteccionismo azucarero y el incesante ritmo de subsidios y compensaciones que, desde 1945, marcaron el involucramiento del Estado nacional en la política agroindustrial. En tal sentido, el Ministro de Salud de la provincia se encargó de subrayar que los empresarios pretendían evadir la responsabilidad de velar por la salud de sus trabajadores, desconociendo "las excepcionales condiciones" en que se desenvolvía la industria azucarera en razón de la protección oficial y los beneficios que tenía asegurados e iban en constante aumento. ${ }^{26}$

Frente a la imposibilidad de resolver el problema en la trama de poder provincial, los industriales apelaron a la nacionalización del conflicto a través de presentaciones efectuadas, entre marzo y mayo de 1947, al Banco Central, la Secretaría de Trabajo y Previsión y la Secretaría de Salud Pública. La nacionalización del conflicto benefició a los empresarios, particularmente la respuesta de la Secretaría de

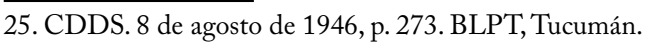

26. La asistencia médica en los establecimientos industriales de Tucumán (marzo de 1947). La Industria Azucarera 641, p. 110. BEEAOC, Tucumán.
Salud Pública de la Nación, al precisar que la ley implicaba transferir a los particulares "casi la totalidad de la población obrera de la Provincia para que se le preste atención médica, derivando así una obligación esencial de las autoridades gubernativas, que sólo se quedan con la facultad de fiscalizar lo que en el terreno de la salud pública realicen los particulares" (Schleh, 1950, p. 193). ${ }^{27}$ En sintonía con esta postura y en procura de avanzar en un acuerdo definitivo, la Secretaría sugería la "paralización" de la ley 2.018. Sin embargo, el gobierno provincial obvió la recomendación, avanzó en el cobro de las multas impuestas a los ingenios y, en noviembre de 1947, se presentó a la justicia para solicitar por vía de apremio el cobro de las mismas.

En las presentaciones judiciales, el gobierno sustentó la improcedencia de los industriales de reclamar la inconstitucionalidad de las leyes por tratarse de una "industria protegida por el Estado y que como tal debe estar sujeta y responder a los fundamentos generales de esa protección. ${ }^{28}$ En este sentido, la noción de “justicia distributiva”, emanada del Laudo Alvear de 1928, se convirtió en el eje argumental de la postura oficial. ${ }^{29}$ En su alegato, el abo-

27. En términos de legislación, la obligatoriedad de construir barrios obreros únicamente en los ingenios administrados por agencias estatales (Ñunorco y Marapa) acotó las tensiones entre los industriales y el gobierno provincial al campo de la salud. El impacto de la política crediticia en la construcción de viviendas en la zona azucarera es un problema de estudio que excede a los objetivos de este artículo pero espera, a futuro, ser recuperado con sistematicidad.

28. Antecedentes sobre las leyes, pp. 83-91, MSPAS, Tucumán.

29. El propósito del Laudo Alvear (1928) fue alcanzar una solución equitativa en el conflicto cañero-industrial por el precio de la caña. El documento definió pautas precisas para determinar el precio de la materia prima 
gado de la provincia transcribió párrafos completos del Laudo, especialmente los referidos a la función social del proteccionismo cuya implementación gravitaba sobre todo el pueblo argentino. En efecto, recuperaba la idea de que una industria incapaz de interpretar el "interés general" no tenía derecho a estar "protegida a costa del pueblo entero de la Nación"

El mejoramiento y asistencia social para todas aquellas personas que con su trabajo personal contribuyan en una gran proporción al engrandecimiento de esta industria protegida, no debe como pretende la parte deudora estar en manos exclusivas del Estado (...) no puede ser alcanzado este beneficio por el 'romántico camino de la dádiva generosa o la beneficencia pública, sino el saludable camino de la justicia que no afecta, sino vigoriza las bases de la industria y responde a los fines económicos y sociales que dan razón de ser a la protección industrial y al sacrificio del consumidor de la República'. ${ }^{30}$

De esta forma, la vigencia del norte social del proteccionismo, sustentado en la noción de "justicia distributiva", fue recuperado para superar su original concepción agrarista y proyectarse sobre el conjunto obrero. Las multas y los apercibimientos a los industriales siguieron

al estipular que el costo promedio de elaboración de una tonelada de caña se aproximaba al costo promedio de una tonelada de materia prima. Así, se ratificaba que el valor de la tonelada de caña debía computarse en el $50 \%$ de su rendimiento en azúcar. Este criterio implicó una trasferencia de ingresos del sector industrial al sector cañero fundamentada en la vigencia del sentido distributivo del proteccionismo azucarero Bravo (2008, pp. 304-312).

30. Antecedentes sobre las leyes, p. 85, MSPAS, Tucumán. su curso, a excepción de los ingenios Marapa y Ñunorco que habían comenzado a construir sus hospitales. ${ }^{31}$

E1 conflicto político desatado con la ley de asistencia médica permite aprehender cómo la coyuntura política, al tiempo que dotó de sentidos el derecho de la salud obrera marcó sus límites y posibilidades. El gobierno provincial concibió como una histórica reparación moral la delegación de una compleja infraestructura sanitaria en los industriales, medida destinada a revertir la concepción del cuidado de la salud obrera como una dádiva empresarial. Esta operación, que suponía avanzar en la construcción de un derecho garantizado por los industriales, se nutrió del histórico sentido social del proteccionismo azucarero. En efecto, la noción de "justicia distributiva", que a fines de la década de 1920 promovió una transferencia de ingresos del sector industrial al cañero, pretendía asumir nuevas connotaciones al impulsar el derrame distributivo de la protección, esta vez, en favor de los obreros.

Así, la ley de asistencia médica intentaba sumarse al vertiginoso avance de la legislación social que, promovida por el Estado nacional, conmovía los cimientos de la política del "buen patrón" y la concepción privada de las relaciones laborales en los ingenios. Sin embargo, la propia coyuntura política marcó los límites de los embates del gobierno provincial. En efecto, cuando la salud de la población recuperaba con inusitada fuerza su connotación de derecho garantizado por el Estado, su transferencia a los industriales resultaba un contrasentido que el propio Estado nacional, a través de la

31. El hospital del ingenio Nuñorco fue inaugurado en agosto de 1947 y el hospital del Marapa comenzó a funcionar un año después. 
Secretaría de Salud Pública, se encargó de remarcar. $^{32}$

En síntesis, los frustrados artilugios legislativos del gobierno provincial impidieron convertir los beneficios, que en materia de vivienda y salud otorgaban los empresarios, en obligaciones. Estos fracasos desnudaron las tensiones que atravesaron la construcción del derecho a la salud y al techo en clave azucarera, en tanto colisionaba con la reformulación del papel estatal y sus ingentes obligaciones sociales. En efecto, mientras el gobierno provincial intentaba delegar en los industriales estas responsabilidades, en febrero de 1947 Perón proclamaba los Derechos del Trabajador, decálogo que contemplaba el derecho a la salud y al bienestar $y$, por ende, a una vivienda digna. Como lo precisó Anahi Ballent (2009), esta formulación distanciaba a la vivienda $-\mathrm{y}$ en nuestro caso también a la salud- de concepciones asociadas al paternalismo y de aquellas que la entendían como un premio a la disciplina y la austeridad de los trabajadores. Al unísono, reforzaba el intervencionismo estatal, en tanto el reconocimiento de estos derechos suponía "el compromiso del Estado como garante de su ejercicio" (p. 64).

32. A nivel nacional, el Plan Quinquenal (1946) y el Plan Analítico de Salud Pública (1947) promovieron la construcción de centros de asistencia médico-hospitalaria en distintas zonas de la provincia de Tucumán. Uno de los más ambiciosos proyectos nacionales fue la creación de un Centro Sanitario y una Ciudad Hospital, propuestas impulsadas por el Ministro de Salud, Ramón Carrillo. El despliegue y desarrollo de las políticas sanitarias de salud durante el primer peronismo en Tucumán fue analizado por Rosales (2017). Asimismo, remitimos a los artículos de Fernández y Rosales (2016) y Jerez (2016).

60

\section{La construcción de derechos en primera persona: las demandas obreras}

El peronismo tucumano procuró disputar la histórica concepción del techo y el cuidado de la salud, concebidos como discrecionales beneficios atados al vínculo contractual con el ingenio, con el propósito de transformarlos en obligaciones patronales. Sin embargo, la imposibilidad de convertir en ley el proyecto de vivienda obrera y el incumplimiento de los industriales frente a la ley de asistencia médica activó la participación y negociación de los obreros, quienes dinamizaron y resignificaron esas demandas a través de los sindicatos de base.

En un contexto de profunda politización, el avance del sindicalismo y la mayor presencia del Estado en los pueblos azucareros promovieron una transferencia de poder que alentó a los obreros a interpelar tradicionales prerrogativas patronales y, al unísono, impugnó la discrecionalidad de los beneficios sociales otorgados por los empresarios. En este sentido, desde 1944 los sindicatos de base denunciaron la falta de infraestructura sanitaria, la carencia de médicos con residencia permanente en los pueblos, la imposibilidad de los enfermos de acceder a ciertos tratamientos y medicinas, así como la falta de atención médica para las mujeres. En este contexto de demandas, por ejemplo, el sindicato del Bella Vista protestó porque el ingenio sólo disponía de un profesional que no realizaba visitas a domicilio, situación que impulsó a los obreros a exigir la remoción del doctor Juan Serra, quien se había negado a "ir a atender" a la madre de un trabajador. ${ }^{33}$

33. Acta 14 del 2 de diciembre 1944, p. 28 y Acta 23 del 23 de septiembre de 1945, p. 64. Libro de Actas del Sindicato de Obreros del Ingenio Bella Vista (1944- 
Asimismo, la asunción de obreros azucareros como diputados y senadores convirtió la interpelación a los industriales en un asunto público, lo que antes se demandada con suma dificultad ahora franqueaba el perímetro de los pueblos azucareros y asumía resonancia pública mediante las intervenciones obreras en la Legislatura. De esta forma, los trabajadores denunciaron la mala atención de algunos médicos quienes, al ser copropietarios o familiares de los industriales, no recetaban medicamentos por un valor superior a los seis pesos o simplemente recomendaban purgantes o cafiaspirinas sin importarles la enfermedad del paciente. Además, como lo señaló el diputado Juan Antonio González, obrero del ingenio Mercedes, "no ha faltado la insolencia de un administrador de ingenio que diga a su médico: sepa que el ingenio está para fabricar bolsas de azúcar, no para curar enfermos". ${ }^{34}$ Inéditamente, la Legislatura tucumana contribuía a modelar el "poder herético" del peronismo (James, 2006).

Una vez promulgada, la ley de asistencia médica actuó como un paraguas reivindicativo que alentó a los obreros a profundizar sus demandas y superar históricos sentidos de los límites. La actuación del Estado provincial como promotor de la ley, la presencia de legisladores obreros y la intermediación de los sindicatos dispuestos a actuar en su cumplimiento coadyuvaron a interpelar a la patronal y posibilitaron que los obreros expresaran, discutieran y demandaran asuntos antes silenciados. Así lo expresó el sindicato del ingenio La Trinidad cuando precisó que el principal motivo de la huelga declarada en mayo de 1948 era lograr

1947), Archivo Privado Manuel Valeros (APMV).

34. CDDS. 19 de diciembre de 1946, p. 856. BLPT, Tucumán. el cumplimiento de la mencionada legislación, porque

bien sabe la clase trabajadora de esta provincia que no hubo ley que reportara en cualquier aspecto para el obrero que no haya sido resistida por los señores industriales. La ley 2.018 en la cual se defiende un derecho humano para salvaguardar la salud de la clase trabajadora (...) es hoy objeto de una resistencia descarada de los señores industriales azucareros, alejándose de las más elementales normas de principios de justicia y de respeto hacia las leyes, aun las que están sancionadas hace ya más de 30 años y que hasta la fecha no se cumplen en su totalidad. ${ }^{35}$

Subvirtiendo tradicionales sentidos de los límites, los obreros de La Trinidad recuperaron la salud como un derecho y denunciaron la histórica inobservancia de la patronal a través de una medida de fuerza. Por su parte, los dirigentes sindicales del Bella Vista visitaron al gobernador Domínguez y se comprometieron a liderar un movimiento de difusión y adhesión obrera a la nueva ley. ${ }^{36}$ Rolando González, secretario general de sindicato bellavisteño, recordaba que con Tito Vaquero, su presidente, "resolvimos apoyar la ley. Entonces salimos por todos los sindicatos para difundirla (...) para pedir el apoyo y para procurar imponerla”. ${ }^{37}$

En este contexto, la Federación obrera fijó su posicionamiento institucional en los Congresos de Trabajadores del Azúcar realizados en

35. Formulan una aclaración dirigentes del Trinidad (14 de mayo de 1948). Trópico. Biblioteca Central de la Universidad Nacional de Tucumán (BCUNT), Tucumán.

36. Obreros del Bella Vista apoyan la ley 2.018 (7 de abril de 1948). Trópico. BCUNT, Tucumán.

37. Entrevista a Rolando González, realizada por Atilio Santillán (hijo), el 30 de octubre de 1999. 
Tucumán en septiembre de 1947 y octubre de 1948. La Federación votó una moción destinada a exigir el estricto cumplimiento de la ley de asistencia médica pero, en sintonía con las concreciones de otros sindicatos del país, abogó por la creación de un policlínico cofinanciado por industriales, cañeros, obreros y empleados de la agroindustria. Asimismo, FOTIA no desbordó con medidas o acciones institucionales los acuerdos alcanzados en estos Congresos, situación que -en un contexto de incumplimiento patronal- implicó delegar en los sindicatos de base las negociaciones destinadas a mejorar el servicio médico en los ingenios.

De esta forma, valiéndose de la estructura descentralizada de la Federación y en función de las necesidades de cada pueblo azucarero, los sindicatos de base articularon sus demandas y diseñaron sus estrategias. Por ejemplo, el sindicato del Esperanza logró firmar un acuerdo que comprometía a la patronal a contratar un médico con residencia permanente en el ingenio, cumplir con la estricta provisión de los medicamentos recetados y, en caso de que el hospital del ingenio no dispusiera de ellos, el reconocimiento de su importe. ${ }^{38} \mathrm{La}$ oficina de Conciliación de la DRSTyP también intercedió en este tipo de demandas en procura de alcanzar acuerdos entre el sindicato y la patronal, así lo hizo frente al conflicto en el ingenio Nueva Baviera, donde los obreros reclamaron que el servicio médico sea más eficiente y se extienda a los días sábados y domingos, ${ }^{39} \mathrm{y}$ en ocasión de las demandas del sindicato de El

38. Obreros de Esperanza firman un convenio (23 de enero de 1948). Trópico, BCUNT, Tucumán.

39. Se trató parte del petitorio de los obreros de N. Baviera (11 de agosto de 1948). Trópico. BCUNT, Tucumán.

62
Manantial destinadas a exigir que los empresarios cumplan con la provisión de medicamentos recetados por el médico y amplíen el servicio de enfermería. ${ }^{40}$

Otras reivindicaciones recurrentes fueron la provisión de camillas para el traslado de los enfermos; la reparación de ambulancias y la compra de instrumentos médicos. En esta tónica, el sindicato del Concepción denunció que el ingenio disponía de un hospital pero carecía de instrumental y personal, "situación que se agravaba en las colonias donde los obreros mueren sin auxilio médico si no disponen de medios para trasladarse hasta el hospital". ${ }^{41}$ También fue denunciada la manera "poco caritativa" con que los médicos trataban a los pacientes, así lo hizo saber el sindicato del Bella Vista cuando reiteró el pedido de traslado o cesantía del profesional debido a "la falta absoluta de atención para con los pacientes". ${ }^{42}$

Una vez aprobada la ley de asistencia médica, el gobernador Domínguez avanzó sobre el problema del techo, beneficio temporal atado a la pervivencia del vínculo contractual con el propietario del ingenio. Sin embargo, antes de que el mandatario enviara el proyecto a la Legislatura, este sensible tema fue reactivado por los sindicatos de base y por los diputados y senadores de extracción fotiana, quienes a través de diversas estrategias -como visitas de inspección a los pueblos azucareros, memoriales presentados a las Cámaras y al gobierno

40. Firmaron un convenio los patronos de El Manantial (14 de agosto de 1948). Trópico. BCUNT, Tucumán.

41. El sindicato de Concepción presentó un memorial a la FOTIA (3 de junio de 1948). Trópico, BCUNT, Tucumán.

42. Obreros de Bella Vista piden la cesantía de un facultativo (24 de enero de 1948). Trópico. BCUNT, Tucumán. 
provincial y denuncias periodísticas- hicieron público el problema del techo. En este contexto, a fines de 1946 el diputado Miguel Ángel Díaz - del azucarero departamento de Cruz Alta- denunció que en el Concepción, 50 familias de la colonia Lolita fueron trasladadas a la localidad del ingenio y arrojadas en corrales, junto con los animales. El diputado, en compañía del Gobernador interino y el Ministro de Gobierno, se trasladó a la fábrica y enfrentó al administrador, quien "alegó ignorancia de lo que allí ocurría”. A continuación, Díaz reivindicó la presencia obrera en la Legislatura y solicitó la conformación de una comisión para recorrer los ingenios e informar de la situación de la vivienda: "estamos en una Cámara cuyos legisladores en su mayoría son obreros de la industria azucarera; por eso mismo debemos buscar el mal y dar el remedio contra esa infamia de la desvergüenza capitalista". ${ }^{43}$

Una práctica similar fue encabezada por el diputado nacional Nerio Rodríguez y el senador provincial Héctor Figueroa Diez, quienes realizaron una visita de inspección al ingenio Bella Vista para luego presentar un extenso memorial al Ministro de Gobierno en el que denunciaban la situación del techo obrero. ${ }^{44} \mathrm{Al}$ unísono, los sindicatos de base exigieron mejoras en las viviendas a través de petitorios y denuncias en la prensa. Por ejemplo, los obreros del ingenio Florida reclamaron "mejorar las condiciones de vivienda de los obreros del ingenio de la localidad, en donde ocurre que en una habitación conviven hasta cinco familias y más personas"; por su parte, el sindicato de

43. CDDS. 31 de octubre de 1946, p. 680. BLPT, Tucumán.

44. Señala deficiencias en las viviendas de los obreros azucareros de Famaillá (27 de abril de 1947). Trópico. BCUNT, Tucumán.
La Trinidad denunció que familias numerosas eran obligadas a "vivir hacinadas en habitaciones pequeñas y cuando las mismas no bastan los mayores deben pernoctar fuera de las mismas". 45

A diferencia de lo sucedido con la iniciativa de asistencia médica, el proyecto de vivienda obrera presentado por Domínguez en la Legislatura no llegó a promulgarse. Sin embargo, el problema del techo, al igual que el de la salud, fue discutido en los Congresos de Trabajadores de la Industria Azucarera. En el primero de ellos, realizado en agosto de 1947, la FOTIA recuperó los derechos de los trabajadores enunciados por Perón a principios de ese año y reivindicó la vivienda como una dimensión del "derecho al bienestar". De esta forma, el Congreso aprobó una moción que obligaba a los industriales a suprimir los conventillos para el personal de fábrica y los ranchos en que vivían los obreros de surco, instalar filtros en la provisión de agua corriente, entubar aguas servidas y construir pozos surgentes y baños. ${ }^{46}$

Sin el respaldo del poder coactivo de la ley, las mejoras vinculadas al techo fueron tramitadas, ingenio por ingenio, por la dirigencia de los sindicatos, situación que generó una densa trama de negociaciones paritarias in situ

45.Reclaman mejores viviendas los obreros del I. La Florida (14 de abril de 1947). Trópico. BCUNT, Tucumán. Trabajadores del Ingenio La Trinidad reclaman mejoras para sus viviendas (8 de mayo de 1947). Trópico. BCUNT, Tucumán.

46. Siguen deliberando los trabajadores del azúcar (31 de agosto de 1947). La Gaceta, p. 7. ADLG, Tucumán; Congreso de obreros de la industria azucarera realizado en Tucumán (septiembre de 1947). La Industria Azucarera 647, p. 453. BEEAOC, Tucumán. Recordemos que los derechos del trabajador, enunciados en febrero de 1947, fueron incorporados en la reformada Constitución nacional de 1949. 
por la veintena de fábricas azucareras. Estas instancias, que se pretendía culminen con la firma de un convenio, se llevaron a cabo con la intervención de la Oficina de Conciliación de la Delegación Regional y su cumplimiento fue supervisado por la Policía de Trabajo. ${ }^{47}$ Por ejemplo, en junio de 1948, el sindicato del ingenio Concepción denunció que "en esta época de reivindicación social, todavía se vive en pocilgas, vivero de ratas y alimañas. En esas pocilgas, en vergonzosa promiscuidad viven familias numerosas y adquiere proporciones alarmantes en época de zafra". ${ }^{48}$ Dos meses después, los representantes de la Compañía Azucarera Tucumana se comprometieron frente al sindicato del Nueva Baviera a "abonar 15 pesos mensuales a los obreros permanentes a los que el ingenio no les otorgue casa, previa presentación de los recibos que los acredite como inquilinos". ${ }^{49}$ La Policía de Trabajo también realizó inspecciones para verificar denuncias gremiales por incumplimiento de convenios que, entre otros aspectos, incumbían al problema del techo. Así sucedió frente a la

47. La Delegación Regional de la Secretaría de Trabajo y Previsión, a través de la Oficina de Conciliación, se proponía "gestionar centralizadamente todos los conflictos laborales (...) controlando el sistema de conciliación y arbitraje entre obreros y patronos, ya sea recibiendo las presentaciones y denuncias o interviniendo de oficio, en forma directa y espontánea en las contiendas que deriven del trabajo". Por su parte, la Policía de Trabajo disponía de capacidad para hacer inspecciones, recibir denuncias, multar a infractores y levantar actas, entre otras. De esta forma, las delegaciones regionales contribuyeron a "jerarquizar la acción estatal en la materia y por otro lado a lograr una gestión más eficiente y profesional de la política social" (Palacio, 2013).

48. El sindicato de Concepción presentó un memorial a la FOTIA (3 de junio de 1948). Trópico. BCUNT, Tucumán.

49. Se trató parte del petitorio de los obreros de N. Baviera (10 de agosto de 1948). Trópico. BCUNT, Tucumán.

64 inobservancia de la patronal de Los Ralos, que no había progresado en la construcción de viviendas acordadas por convenio, estipulándose una prórroga para la realización de las mis$\operatorname{mas}^{50}$ y frente a la solicitud del propietario de ingenio El Manantial, quien solicitó posponer la construcción de las viviendas acordadas por convenio. ${ }^{51}$

A fines de 1949, como desenlace de la gran huelga azucarera, la Confederación General del Trabajo (en adelante, CGT) intervino la FOTIA, medida que se extendió hasta 1955. Los infructuosos intentos de reorganizar el sindicalismo azucarero y las tensiones inherentes a esta decisión (especialmente la defensa de la "autonomía" de los sindicatos de base frente a la propuesta centralizadora de la intervención) se inscribieron en un proceso de racionalización y eficiencia productiva que, alentado por el Estado nacional, disminuyó sensiblemente el poder obrero. Sin embargo, estos condicionamientos no obturaron la capacidad negociadora de los sindicatos, que continuaron con las negociaciones destinadas a mejorarlas condiciones socio-laborales en los pueblos azucareros. ${ }^{52}$

50. Cumplió procedimientos la Policía del Trabajo (30 de enero de 1948). Trópico. BCUNT, Tucumán.

51. Intensa acción cumple la Policía de Trabajo (23 de abril de 1949). La Gaceta. ADLG, Tucumán.

52. En 1950 el sindicato de Los Ralos negoció la construcción de 18 casas de material para los obreros de fábrica y reparaciones en las viviendas los trabajadores de cerco; las autoridades del Corona informaban el otorgamiento de préstamos de la administración para que los trabajadores levanten sus viviendas y el arreglo y reparación de múltiples casas de los obreros; el sindicato del Amalia destacaba la construcción de viviendas para los peones de la colonia y el de Mercedes comunicaba la refacción de casas y la construcción de baños para el personal de surco. Confederación General del Trabajo (1950, pp. 47-53). 
Las demandas obreras, entre ellas las vinculadas a la salud y al techo, encontraron una nueva forma de expresión en la convocatoria que Juan D. Perón lanzó en diciembre de 1951 para que personas e instituciones -en especial los sindicatos- le envíen sugerencias, las que serían evaluadas y posiblemente incorporadas al Segundo Plan Quinquenal. El llamado presidencial alteró la cotidianeidad de las comunidades azucareras: los sindicatos convocaron a reuniones para discutir las propuestas que le harían llegar a Perón; algunos obreros prefirieron evitar esta intermediación y dirigieron sus cartas a título personal; las mujeres también fueron interpeladas y le escribieron al Presidente para expresar sus problemas y los de su familia; centros vecinales, curas, delegadas censistas y maestras de los pueblos también hicieron llegar sus misivas.

En enero de 1952, Anacleto Ortega fue uno de los obreros, quien movilizado por la convocatoria decidió escribirle a Perón para solicitarle la expropiación del ingenio donde trabajaba, el Leales. Entre sus argumentos señalaba el hacinamiento en que vivía la familia obrera, especialmente de los trabajadores de surco, producto de la conculcación que los empresarios hacían de las leyes vigentes. Por un lado, denunciaba que el ingenio carecía "de viviendas cómodas e higiénicas como dice la ley 10.644 y los derechos del trabajador que nos ampara la Constitución Nacional". ${ }^{53}$ También subrayaba la deficiente atención médica porque "tampoco hay buenos medicamentos curativos, la mayo-

53. El decreto 10.644, promulgado en 1944, fijaba los salarios de los obreros permanentes y temporarios y para este último actor, el más vulnerable de la cadena productiva, establecía las condiciones de trabajo, las instancias de resolución de los conflictos y los aspectos vinculados a la salud, la educación y la vivienda. Véase: Ostengo de Ahumada (1969, p. 223). ría que usan son calmantes. El hospital es sala de primero auxilios". Por ende, concluía que los industriales ignoraban las leyes provinciales 2.018 y 2.029 , aprobadas en $1947 . .^{54}$ Así, las demandas por derechos fundían las nociones de lo injusto -asociadas con las inobservancias de la patronal- con el conocimiento de la legislación promovida por el peronismo, operación que desvinculaba la salud y la vivienda de la concepción privada y asistencialista defendida por el empresariado tucumano.

Las misivas que llegaron de los pueblos azucareros a la Casa de Gobierno se multiplicaron. Así, los trabajadores del ingenio San Pablo le escribieron a Perón para precisarle que las injusticias vinculadas al techo eran una consecuencia dolorosa del "régimen antisocial y despiadadamente inhumano" vivido por culpa de los "oligarcas", quienes ubicaban a la familia obrera en chozas miserables y horribles conventillos, espacios que contrastaban con el lujo y la comodidad en que otros vivían. ${ }^{55}$ En sintonía, el sindicato del Mercedes solicitaba el cumplimiento de la ley de asistencia médica, la creación de un policlínico para los obreros del azúcar y la construcción de viviendas económicas. Para ellos, reemplazar las pocilgas "que no podían ser habitadas por seres humanos" contribuiría a mejorar la "condición de vida a que tiene derecho todo trabajador. ${ }^{, 56}$ Desde el ingenio Los Ralos, el sindicato le escribió al Presidente reclamando la expropiación de tierras para construir un barrio obrero que subsane la carencia de vivienda propia, "por ser toda la

54. Expediente 9.878, caja 53, FSLTPN, DI-AGN, Buenos Aires.

55. Expediente 11.289, caja 53, FSLTPN, DI-AGN, Buenos Aires.

56. Expediente 16.146, caja 344, FSLTPN, DI-AGN, Buenos Aires. 
tierra de propiedad de los dueños del Ingenio quienes se niegan a toda venta", situación que empeoraba cuando los trabajadores se jubilaban o eran despedidos porque no existían "casas para alquilar" en el pueblo azucarero. ${ }^{57} \mathrm{Del}$ Leales también denunciaban que los médicos "que traen los señores dueños de las fábricas son los que andan como bólido que no tiene cuerda (...) no sirven, en lugar de curarnos, si nos encontramos un poquito enfermos él trata de liquidarnos". 58

En síntesis, estas cartas evidencian cómo la coyuntura peronista alentó un conjunto de demandas que posibilitan recuperar los históricos sentidos de lo justo forjados en la experiencia obrera azucarera y cómo el avance de la legislación socio-laboral en sintonía con el reposicionamiento estatal coadyuvó a disputar el sentido de la salud y la vivienda. Así, de la arraigada concepción que los ubicaba como discrecionales beneficios empresariales se transitó a una noción en la que privaba la idea de derecho. Sin embargo, esta nueva forma de articular las demandas estuvo atravesada por múltiples tensiones. Por un lado, las devenidas del posicionamiento del poder provincial, empecinado en hacer recaer en los industriales la total asunción de los mismos. Por otro, el ingente posicionamiento del Estado como garante de estos derechos y, por ende, los límites que las agencias nacionales impusieron, especialmente, a la legislación sanitaria; finalmente, la resistencia de los empresarios y la histórica defensa del techo y la salud como expresión de sus políticas asistenciales y, en tal sentido,

57. Expediente 7.898, caja 62, FSLTPN, DI-AGN, Buenos Aires.

58. Expediente 7.912, caja 311, FSLTPN, DI-AGN, Buenos Aires.

66 refractarios a cualquier intento de convertirlos en obligaciones.

\section{Conclusiones}

En los pueblos azucareros el techo y el cuidado de la salud obrera se configuraron como beneficios discrecionales otorgados por la patronal y atados a la continuidad del vínculo contractual con el ingenio. Para el conjunto de los trabajadores, la contracara de esta concepción asistencial y privada se tradujo en disímiles condiciones de supervivencia -multiplicadas por la veintena de fábricas- y un común sentimiento de vulnerabilidad y desposesión.

La trama del asistencialismo social fue sensiblemente cuestionada por el gobierno peronista provincial que procuró convertir la asistencia médica y la vivienda obrera en obligaciones garantidas por los industriales. Los históricos incumplimientos de la patronal vinculados a la ley de salud de 1925; la defensa y reactualización del carácter distributivo del proteccionismo azucarero; el rol tutelar del Estado nacional en la agroindustria y el avance del poder obrero en la puja intersectorial impulsaron, en 1947, una nueva ley de asistencia médica y alentaron la presentación de un proyecto de construcción de vivienda obrera que también recaía en los industriales. Esta trama legislativa, reflejo del nuevo "poder de clase", expresó un profundo cuestionamiento a las históricas concepciones empresariales y coadyuvó a poner en locución sentidos de lo justo forjados en la experiencia obrera. $^{59}$

59. Recuperamos la propuesta de Thompson (2002), quien advirtió cómo la ley, directa o indirectamente, contribuyó a imponer un poder de clase y fue uno de los principales escenarios de conflicto en la Inglaterra de los 
Sin embargo, frente al progresivo involucramiento del Estado como garante de derechos - expresado en la inclusión de la salud y la vivienda como dimensiones de los Derechos del Trabajador (1947), que dos años después alcanzaron rango constitucional- la avanzada del peronismo tucumano encontró su propio límite. Así, la transferencia de estas obligaciones que el Estado asumía como propias tensionó el mapa político y fue la Secretaría de Salud de la Nación la encargada de precisar los límites de sus "esenciales obligaciones", posicionamiento que fijó el destino de la ley de asistencia médica. Ahora bien, más allá de las limitaciones de aplicación de la mencionada ley y la imposibilidad de discutir el proyecto de vivienda obrera, la creciente politización de estos tópicos impulsó un campo de fuerzas que permitió a los obreros a disputar el sentido de los beneficios en favor de una nueva concepción sustentada en la idea de derecho. Así, en los pueblos azucareros, los sindicatos de base alentaron demandas que nos invitan a desandar la totalizante y universal noción del derecho y posibilitan recuperar "desde abajo" la particular construcción del cuidado de la salud y la vivienda obrera durante el primer peronismo.

$$
\propto \tilde{e} \propto
$$

Recibido: 07-02-2018

Aceptado: 11-05-2018

Publicado: 07-12-2018

siglos XVI y XVII (pp. 494-506). 


\section{Referencias Bibliográficas}

Ballent, A. (2009). Las huellas de la politica. Vivienda, ciudad peronismo en Buenos Aires, 1943-1955. Universidad de Quilmes: Prometeo.

Bravo, Ma. C. (2008). Campesinos, azúcar y política: politica: cañeros, acción corporativa y vida politica en Tucumán (1895-1930). Rosario: Prohistoria.

Bravo, Ma. C. y Gutiérrez, F. (2014). La política azucarera argentina: de la concertación sectorial al tutelaje estatal (1928-1949). H-Industria, 14(8), 155-188.

Bustelo, J. (2016). Los ingenios mixtos en Tucumán durante el primer peronismo, 1943-1955.H-industri@, 19(10), 23-49. Recuperado de http://ojs.econ.uba.ar/ojs/index.php/H-ind/article/view/930

Campi, D. (2009). Contrastes cotidianos. Los ingenios del norte argentino como complejos socioculturales, 1870-1930. Varia Historia, 25(41), 245-267. Recuperado de http:/www.scielo.br/pdf/vh/v25n41/ v25n41a13.pdf

Fernández, Ma. E. y Rosales, Ma. del C. (2016). Trayectorias locales y proyecciones nacionales en el proceso de centralización sanitaria en Tucumán (1900-1950). Trabajos y Comunicaciones, 44. Recuperado de http://www.trabajosycomunicaciones.fahce.unlp.edu.ar/article/view/TyCe024

Centro Azucarero Argentino (1943). Asistencia social en la industria azucarera. Buenos Aires: Establecimiento Gráfico Ferrari Hermanos.

Gutiérrez, F. (2014). La irrupción del poder obrero en los ingenios azucareros: avances, límites y cuestionamientos. Tucumán, 1944-1955. Quinto Sol, 18(2), 135-157. Recuperado de http://www.redalyc.org/ articulo.oa? $\mathrm{id}=23133479003$

Gutiérrez, F. (2016). Clase y masculinidad en la construcción de derechos laborales y la división del trabajo azucarero. Tucumán durante el primer peronismo. En Andújar, A., Caruso, L., Gutiérrez, F., Palermo, S., Pita, V. y Schettini, C. (Comps.), Vivir con lo justo. Estudios de bistoria social del trabajo en perspectiva de género. Argentina, siglos XIX y XX. Rosario: Prohistoria.

Confederación General del Trabajo (1950). Intervención de la Confederación General del Trabajo ante la FOTIA. Buenos Aires: Confederación General del Trabajo.

James, D. (2006). Resistencia e integración. El peronismo y la clase trabajadora argentina, 1946-1976. Buenos Aires: Siglo XXI.

Jerez, M. (2016). La política sanitaria del peronismo en Jujuy (1946-1952). Emilio Navea y la transformación del sistema de salud pública. Trabajos y Comunicaciones, 44. Recuperado de http://www.trabajosycomunicaciones.fahce.unlp.edu.ar/article/view/TyCe025 
Jerez, M. (2017). Los problemas de Jujuy son la tierra y la vivienda. La ley de vivienda obrera rural durante el primer peronismo en Jujuy (Argentina). Historia Caribe, XII(31), 293-326. http://dx.doi.org/10.15648/ hc.31.2017.10

Landaburu, A. (2014). Los empresarios azucareros y la cuestión social. Tucumán, 1904-1930 (Tesis doctoral inédita). Universidad Nacional de Tucumán, Tucumán, Argentina.

Landaburu, A. y Lenis, Ma. (2015). Asociacionismo, empresarios azucareros y cuestión social en Tucumán: las huelgas azucareras, 1919-1923. En J. M. Cerdá, G. Guadarrama, Ma. D. Lorenzo, y B. Moreyra (Coords.), El auxilio en las ciudades. Instituciones, actores y modelos de protección social. Argentina y México. Siglos XIX y XX (pp. 429-456). México: El Colegio Mexiquense, A.C. y Centro de Estudios Históricos "Prof. Carlos S. A. Segreti".

Mackinnon, M. (2003). El protagonismo del movimiento obrero tucumano en la formación del Partido Peronista (1945-1950). En S. Grez Toso, F. Zapata y Autora (Eds.), Formas tempranas de organización obrera (pp. 93-121). Buenos Aires: La Crujía-Instituto Torcuato Di Tella.

Ostengo de Ahumada, A. Ma.(1969). La Legislación laboral en Tucumán. Recopilación ordenada de leyes, decretos y resoluciones sobre el derecho del trabajo y seguridad social, 1939-1969. Tucumán: Universidad Nacional de Tucumán.

Palacio, J. M. (2013). El peronismo y la invención de la justicia del trabajo en la Argentina. Nuevo Mundo Mundos Nuevos. Recuperado de: http://nuevomundo.revues.org/65765

Rosales, Ma. del C. (2017). La salud como derecho ciudadano. Las políticas de salud en Tucumán durante el primer peronismo (1943-1955). En Ma. E. Fernández, (Coord.), La salud: instituciones, espacios y actores (pp. 81-114). Buenos Aires: Imago Mundi.

Rubinstein, G. (2005). Los sindicatos azucareros en los orígenes del peronismo tucumano. Tucumán: Universidad Nacional de Tucumán, Facultad de Ciencias Económicas.

Schleh, E. (1950). Compilación legal sobre el azúcar. Legislación nacional, tomo XII. Buenos Aires: Establecimiento Gráfico Ferrari Hermanos.

Thompson, E. (2002). El imperio de la ley (en Obra Esencial. Edward Palmer Thompson). Barcelona: Crítica.

Ullivarri, Ma. (2011). Sindicatos en la 'capital del azúcar'. Organización y lucha en el mundo del trabajo de la provincia de Tucumán (Argentina), 1930-1943. Historia Agraria, 55, 101-133. Recuperado de http://repositori.uji.es/xmlui/bitstream/handle/10234/149725/2011_55_101_133.pdf?sequence=1\&isAllowed=y

Ullivarri, Ma. (2013). Trabajadores, Estado y derechos. E1 Departamento Provincial de Trabajo tucumano durante la década de 1930. En Lobato, M. y Suriano J. (Comps.), Las instituciones laborales en la Argentina (1900-1955) (pp. 155-176). Buenos Aires: Edhasa. 
Ullivarri, Ma. (2016). Demandas de asistencia médica en los territorios azucareros. Tucumán en tiempos de entreguerras. Varia Historia, 32(60), 861-898. Recuperado de http://www.scielo.br/scielo.php?script=sci_arttext\&pid=S0104-87752016000300861

Ullivarri, Ma. (2017). Disputas en torno a las políticas públicas, la legislación laboral y el bienestar obrero en la industria azucarera de Tucumán/Argentina (1917-1943). Historia Caribe, XII(31), 259-292. http:// dx.doi. org/10.15648/hc.31.2017.9 